\title{
CORROSION RELATED PROPERTY IMPROVEMENT FOR CEMENT MORTAR APPLIED TO MARINE ENVIRONMENT
}

\author{
Pei-Ying Chung \\ Department of Information Management, Mei-Ho University, Pingtung County, Taiwan, R.O.C \\ Hsien Hua Lee \\ Department of Marine Environment \& Engineering, National Sun Yat-Sen University, Kaohsiung County, Taiwan, R.O.C, \\ hhlee@mail.nsysu.edu.tw \\ Meng-Syun Yu \\ Department of Marine Environment \& Engineering, National Sun Yat-Sen University, Kaohsiung County, Taiwan, R.O.C
}

Follow this and additional works at: https://jmstt.ntou.edu.tw/journal

Part of the Other Civil and Environmental Engineering Commons

\author{
Recommended Citation \\ Chung, Pei-Ying; Lee, Hsien Hua; and Yu, Meng-Syun (2012) "CORROSION RELATED PROPERTY IMPROVEMENT FOR \\ CEMENT MORTAR APPLIED TO MARINE ENVIRONMENT," Journal of Marine Science and Technology. Vol. 20: Iss. 2, \\ Article 3. \\ DOI: $10.51400 / 2709-6998.1831$ \\ Available at: https://jmstt.ntou.edu.tw/journal/vol20/iss2/3 \\ This Research Article is brought to you for free and open access by Journal of Marine Science and Technology. It has been \\ accepted for inclusion in Journal of Marine Science and Technology by an authorized editor of Journal of Marine Science and \\ Technology.
}




\section{CORROSION RELATED PROPERTY IMPROVEMENT FOR CEMENT MORTAR}

APPLIED TO MARINE ENVIRONMENT

\section{Acknowledgements}

This paper has been financially supported in part by the National Science Council of Republic of China (Taiwan) under grants NSC95-2221-E110-144. It is gratefully acknowledged here. 


\title{
CORROSION RELATED PROPERTY IMPROVEMENT FOR CEMENT MORTAR APPLIED TO MARINE ENVIRONMENT
}

\author{
Pei-Ying Chung ${ }^{1}$, Hsien Hua Lee ${ }^{2}$, and Meng-Syun $\mathrm{Yu}^{2}$
}

Key words: bamboo charcoal, cement mortar, marine concrete, concrete deterioration.

\begin{abstract}
It is a well known fact that infrastructures in marine environments are subjected to corrosion attacks all the time. The most severe corrosion happens to the steel materials that are directly exposed in the marine environment, particularly for the portion exposed in the splash zone, where the air (oxygen) is embroiled with water causing a wet and dry alternately exerting environment. The most widely used material of marine infrastructure, such as reinforced concrete, is also subjected to deterioration damage from the marine environment. In this way, it weakens the impermeability of the material so that the sea water is allowed to penetrate through the protection layer of the structural member and therefore, the reinforced bars embedded in the concrete are corroded. In this study, several experimental tests were designed and carried out to examine the applicability of a scheme by replacing a small amount of aggregates with the bamboo charcoal to improve the characteristics of cement mortar utilized in infrastructures in marine environment. Tests including the properties of fresh mixed cement mortar, the compressive strength test, sulfate-resistant capability tests, chloride-block tests and permeability relevant tests were carried out to investigate the influence of bamboo charcoal on the mechanical properties of the cement mortar. It was found that a small amount of replacement of fine aggregate with bamboo charcoal may greatly improve the properties of cement mortar applied to infrastructures in marine environment. The material deterioration may be mitigated by the improvements of moisture impermeability and chloride blocking effects due to the application of bamboo charcoals.
\end{abstract}

Paper submitted 05/18/10; accepted 07/20/10. Author for correspondence: Hsien-Hua Lee (e-mail: hhlee@ mail.nsysu.edu.tw).

${ }^{I}$ Department of Information Management, Mei-Ho University, Pingtung County, Taiwan, R.O.C.

${ }^{2}$ Department of Marine Environment \& Engineering, National Sun Yat-Sen University, Kaohsiung County, Taiwan, R.O.C.

\section{INTRODUCTION}

For infrastructure construction located in marine environments, maintaining good durability for the structures always imposes serious challenges. The deterioration of the material, such as the neutralization of the concrete material, the corrosion in the ferro-material and many other erosive attacks due to the presence of sulfate and acidic elements in the environment are always major problems for the engineer to deal with $[13,14,15]$. Reinforced concrete, due to its high strength, ease of forming into many kinds of shapes, good resistance to water and economic availability, is the material most widely used for engineering constructions. Particularly for construction in the harbor area, there are many types of wharf structural systems. They are designed based on the special properties of concrete such as the massive weight type of wharf structural system, the caisson type of wharf structural system and the bridge-type system. However, the neutralization of concrete due to the permeation of chloride, which gradually deteriorates the concrete, damages the impermeability and then reduces the strength is quite common for harbor infrastructures $[10,16,19]$.

Concrete exposed to marine environment may deteriorate as a result of combined effects of chemical actions of seawater constituents on cement hydration products, alkali-aggregate expansion, crystalization pressure of salts within concrete, corrosion of embedded steel in reinforced or prestressed members, and physical erosion due to waves action and floating objectives [18]. The corrosion in the reinforced steel bars embedded in the concrete is mostly due to the intrusion of sea water, which penetrates through the small cracks or the deteriorated concrete. Other factors such as the sulfate, chloride and acidic elements can also worsen the problems. Therefore, a method to protect the reinforced concrete in the marine environment from damages due to material deterioration and corrosion is always a major concern when a marine infrastructure is being designed. The most effective way will be by improving the impermeability of the concrete material and at the same time ensuring that the other positive properties of the material will not be sacrificed.

To improve the impermeability of the concrete material, usually a pozzolanic material is used [17] because of its finely divided form and its ability to react with calcium hydroxide in 
the presence of moisture so that the larger capillary pores can be filled up. In this way, the impermeability of concrete material can be enhanced. This study, by applying the bamboo charcoal in cement mortar and then the concrete, will provide an alternative scheme to improve the impermeability of the concrete. Furthermore, by utilizing the adsorption ability of bamboo charcoal to chloride, which penetrates into the material and causes a neutralization reaction, the concrete deterioration may be mitigated as well. The bamboo charcoal basically is the carbonized bamboo formed by processing in a kiln through temperatures around $900^{\circ} \mathrm{C}$. Besides the carbon and hydrogen, many other chemical compounds are presented such as $\mathrm{K}_{2} \mathrm{O}, \mathrm{MgO}, \mathrm{P}_{2} \mathrm{O}_{5}, \mathrm{CaO}$ and $\mathrm{Fe}_{2} \mathrm{O}_{3}$ [11]. The BET specific surface area of bamboo charcoal may reach as high as $1200 \mathrm{~m}^{2} / \mathrm{g}$ and this makes bamboo charcoal a good material with high adsorption capacity to chlorides and other harmful elements.

In this study, the idea is by replacing various levels of small amount of fine aggregate in the cement mortar with the bamboo charcoal to improve the impermeability, sulfate resistant capability and the chloride adsorption ability for the material. Several levels of water-cement ratio were also designed and the laboratory tests were performed to examine the influence on both the basic properties and the enhanced characteristics of concrete. Tests including the compressive strength test and permeability relevant tests were carried out to investigate the influence of bamboo charcoal as the partial replacement for the aggregates on the mechanical properties of the cement mortar. In addition, in order to know the blocking effect to the harmful chemical ingredients such as chlorine in the hydrated cement paste and the resistant ability to sulfate attack, tests against chloride and tests for sulfate resistance capacity were both designed and carried out. It was found that the partial replacement of fine aggregate with bamboo charcoal has encouraging effects on both the prevention of material deterioration and impermeability of concrete in marine environments.

\section{BASIC THEOREMS}

\section{The Main Compositions of Cement}

The main compositions of Portland cement include the dicalcium silicate $\left(\mathrm{C}_{2} \mathrm{~S}\right)$, tricalcium silicate $\left(\mathrm{C}_{3} \mathrm{~S}\right)$, tricalcium aluminate $\left(\mathrm{C}_{3} \mathrm{~A}\right)$ and calcium ferroaluminate $\left(\mathrm{C}_{4} \mathrm{AF}\right)$. After hydration reactions, the hydrated productions of these compounds act as a binder to bind the aggregates together and this is called concrete. After the curing and hardening processes, the concrete becomes a material with high strength. Cement mortar is concrete without course aggregates. Without course aggregates, the chemical reactions of cement hydration will be the same. However, variations or replacements of aggregate proportions in the design of concrete mixture may cause variations of internal structures of the hardened concrete.

\section{The Process of Cement Hydration}

The hydration of cement compounds can be divided into two major parts, namely, the silicate hydration and the aluminate hydration. The physical features of the hydration process indicate the change in the material from aqueous, viscous fluid, plastic form, to hardened solid. The variations in mechanical properties including the consistency, the cohesiveness, the plasticity and the strength along with the hydration process are also important for the work of concrete placement and compaction.

The reaction of $\mathrm{C}_{3} \mathrm{~A}$ with water is immediate. Crystalline hydrates $\mathrm{C}_{3} \mathrm{AH}_{6}, \mathrm{C}_{4} \mathrm{AH}_{19}$, and $\mathrm{C}_{2} \mathrm{AH}_{8}$ are formed quickly with liberation of the heat of hydration. However, in the presence of gypsum, the process of hydration of $\mathrm{C}_{3} \mathrm{~A}$ may be retarded. Depending on the concentration of aluminate and sulfate ions in solution, the precipitating crystalline product is either the calcium aluminate trisulfate hydrate or the calcium aluminate monosulfate hydrate. Normally a calcium aluminate trisulfate hydrate is produced firstly as shown in Eq. (1), which is a short prismatic needles called ettringite. Later on due to the increase of aluminate concentration, the ettringite become unstable and gradually convert into a monotype aluminate sulfate hydrate as shown in Eq. (2), a thin hexagonal plate crystal.

$$
\begin{gathered}
C_{3} A+3 C \bar{S} H_{2}+26 H \stackrel{\Delta H}{\longrightarrow} C_{3} A \cdot 3 C \bar{S} \cdot H_{32} \\
C_{3} A \cdot 3 C \bar{S} \cdot H_{32}+2 C_{3} A+4 H \longrightarrow 3 C_{3} A \cdot C \bar{S} \cdot 12 H
\end{gathered}
$$

The hydration of the silicates produces a family of calcium silicate hydrates which are the main portions contributing the strength and hardness for the material. The stoichiometric reactions for the $\mathrm{C}_{3} \mathrm{~S}$ and $\mathrm{C}_{2} \mathrm{~S}$ with water may be presented as follows,

$$
\begin{gathered}
2 \mathrm{C}_{3} \mathrm{~S}+6 \mathrm{H}+26 \mathrm{H} \stackrel{\Delta H}{\longrightarrow} \mathrm{C}_{3} \mathrm{~S}_{2} \mathrm{H}_{3}+3 \mathrm{CH} \\
2 \mathrm{C}_{2} \mathrm{~S}+4 \mathrm{H} \stackrel{\Delta H}{\longrightarrow} \mathrm{C}_{3} \mathrm{~S}_{2} \mathrm{H}_{3}+\mathrm{CH}
\end{gathered}
$$

It is noticed that similar reaction products are formed on hydration of both calcium silicates in the cement. However, there are some differences between these two sets of reactions such as hydration of $\mathrm{C}_{3} \mathrm{~S}$ would produce $61 \% \mathrm{C}_{3} \mathrm{~S}_{2} \mathrm{H}_{3}$ and $39 \%$ calcium hydroxide, whereas the hydration of $\mathrm{C}_{2} \mathrm{~S}$ would produce $82 \% \quad \mathrm{C}_{3} \mathrm{~S}_{2} \mathrm{H}_{3}$ and $18 \%$ calcium hydroxide. The presence of calcium hydroxide is detrimental to the concrete located in sulfate and acidic environments and therefore, the hydration products of $\mathrm{C}_{2} \mathrm{~S}$ may have better durability. The adhesive property of hydrated cement paste is mainly due to the formation of the calcium silicate hydrates $(\mathrm{C}-\mathrm{S}-\mathrm{H})$, which are produced in larger amount in the hydration products of $\mathrm{C}_{2} \mathrm{~S}$.

\section{The Influence of Chloride on Concrete and Steel}

The intrusion of chloride ions can be found distributed in the concrete through capillary adsorption and diffusion. When 
the amount of chloride increases up to a level, the calcium in $\mathrm{C}-\mathrm{S}-\mathrm{H}$ paste will be reacted with chloride ions and form a highly soluble product, calcium chloride $\mathrm{CaCl}_{2}$. In this way, the C-S-H paste will be gradually deteriorated and then the internal pores of the concrete or cement mortar are increased. The permeability of the material is then increased and the strength will be reduced subsequently. On the other way, the chloride ions in the concrete material may further damage the passive film of the steel embedded in the concrete, which is important for the steel to protect it from recurrent corrosion as shown as follows. The stoichiometric reaction for the recurrent corrosion mechanism is presented as

$$
\begin{gathered}
2 \mathrm{Fe}+6 \mathrm{Cl}^{-} \rightarrow 2 \mathrm{FeCl}_{3}^{-}+4 e^{-} \\
2 \mathrm{FeCl}_{3}^{-}+2 \mathrm{OH}^{-} \rightarrow \mathrm{Fe}(\mathrm{OH})_{2}+3 \mathrm{Cl}^{-} \\
\mathrm{Fe}(\mathrm{OH})_{2}+\frac{1}{2} \mathrm{H}_{2} \mathrm{O}+\frac{1}{4} \mathrm{O}_{2} \rightarrow \mathrm{Fe}(\mathrm{OH})_{3}
\end{gathered}
$$

It is noticed from these equations that the hydroxyl ions will also be consumed by the chloride ions as shown in Eq. (6) and reduce the $\mathrm{pH}$ value while the chloride ions produced at cathode will keep staying on the surface of steel and make the recurrent corrosion process over and over again.

\section{The Voids in Concrete Material and Bamboo Charcoal Application}

The internal structure of concrete can be divided into three phases generally: hydrated cement paste (hcp), aggregate and transition zone between the hcp and aggregate. In the macroscopic view, concrete can actually be considered as a twophase material including both hcp and aggregate since the transition zone around the aggregate is very thin. The hydrated cement paste acts as a binder to bind the aggregates together. In the hydrated cement paste, there are solids, voids and water contained in the voids. The solids are composed of calcium silicate hydrate, calcium hydroxide, calcium sulfoaluminates, calcium sulfoferroaluminates and other unhydrated clinker grains. The voids may include the interlayer space in calcium silicate hydrates (C-S-H), capillary voids and air voids, of which the dimension can be ranged from nanometer to millimeter. These voids, particularly the capillary voids contribute to the porosity of the concrete material and are the major detriment to the strength and impermeability.

For the micro-structures of the hydrated cement paste, there are several models presenting a similar formation of chemical compounds but different structure form [20]. Powers-Brunauer model simulates the interlayer structure as a layer with regular form as shown in Fig. 1(a). The decrease of interlayer water due to a low humidity condition may cause a permanent deformation of the layer. Feldman-Sereda model simulates the interlayer as an irregular layer as shown in Fig. 1(b), where the loss of the interlayer water will not cause a permanent

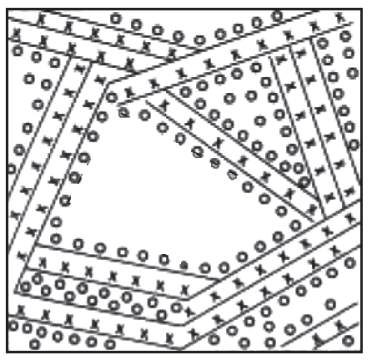

(a)

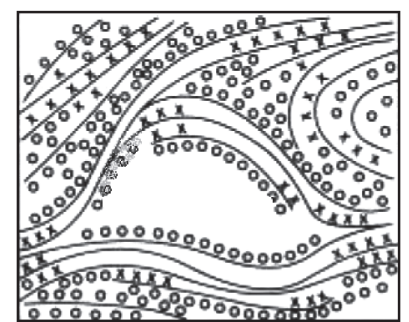

(b)

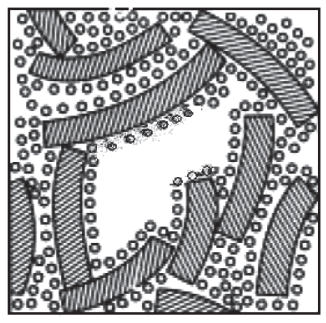

(c)

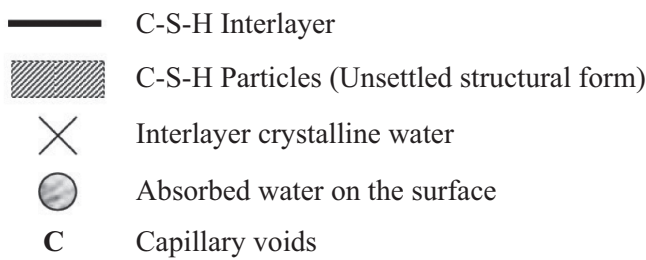

Fig. 1. The modeled micro-structures of the hydrated cement paste.

deformation for the material. It is because the voids between $\mathrm{C}-\mathrm{S}-\mathrm{H}$ layers are flexible with respect to the interlayer water. The $3^{\text {rd }}$ model is Munich model as shown in Fig. 1(c). The C-S-H layers are constituted of particles, of which the binding force is determined by the amount of interlayer water. When the interlayer water is increased, the binding force mainly from wan der Waals force will be reduced.

Based on the properties of the bamboo charcoal that the particle is small (in terms of $\mu \mathrm{m}$ ), the BET specific surface area of unit weight is large and the ability to adsorb the chloride is significant, it is expected that due to a small amount of replacement of the fine aggregate by the bamboo charcoal, the impermeability of the cement mortar can be improved and the penetration rate of chloride can be reduced. Therefore, the material deterioration for the concrete structures located in marine environments, particularly due to the chloride attacks may be effectively reduced and the corrosion of the reinforced steel bars embedded in the concrete material can be mitigated.

\section{EXPERIMENTAL TESTING PROGRAM}

\section{Specimen Design}

In the design of the testing specimen, two important factors were concerned: firstly, the improvements of the environ- 
mental sustainability of the cement mortar must not influence the other characteristics of the concrete; secondly, under the condition of achieving the goal of this study, the replacement of the bamboo charcoal must be as little as possible due to economic reasons.

Four replacement ratios of the bamboo charcoal to the fine aggregate were designed, namely, $0 \%, 3 \%, 5 \%, 7 \%$, which are rather small compared to the proportion of fine aggregates in the cement mortar. Whether the strength of the cement mortar might be influenced by the charcoal replacement is a major concern in this study. Since the strength is normally related to the water/cement ratio, therefore, the variation of water/ cement ratios is considered as an important factor for the study. Three water/cement ratios were used for the tests, which based on ASTM C109/109M-08 include the normal w/c ratio 0.48 (as group B), high w/c ratio 0.55 (as group C) and low w/c ratio 0.40 (as group $\mathrm{A}$ ). Then totally, 12 sets of specimens were designed and tested for each specific property of the material.

\section{Testing Set-up}

In order to understand the engineering influence on the properties of the cement mortar with the addition of the bamboo charcoal, a series of experimental tests were performed. Since the particle-dimension of the bamboo charcoal used in this study is rather small compared to the replaced fine aggregates, it is assumed that some larger voids of the cement mortar induced from the hydration procedure such as the voids shown in Fig. 1 can be filled up by the particles of bamboo charcoal. Therefore, the permeability of the cement mortar can be reduced, which may also increase the strength of the mortar.

Before tests for the hardened specimens, the tests for fresh mixture of cement mortar were carried out first. The flowtable testing [5] for the fresh mortar and the setting time [4, 6] were both examined. For the hardened mortar, the compressive strength tests [2] were carried out when the testing specimens were cured for 28 days saturated in the lime water. Due to the decrease of the permeability and the possible adsorption of the chloride by the bamboo charcoal, it is also expected that the resistance to the chloride compounds can also be improved [12]. So the corresponding tests for the permeability and the chloride-blocking were also carried out.

In order to know the durability for the charcoal added cement mortar, the tests for the sulfate resistant capability were further performed. Similarly, specimens of three various water/cement ratios along with four ratios of replacement of bamboo charcoals were soaked into the solution of sodium sulfate and then dried out alternately for five cycles [3]. Then the distortion and volume variation of the specimen were examined and recorded, the weight-loss of the specimen was measured, the increment of moisture absorption rate was evaluated and compressive strength of the specimen was also taken. All of these data were then combined together to construct a 3-D frame-figure that can indicate the durability of the cement mortar resisting against the sulfate attack.

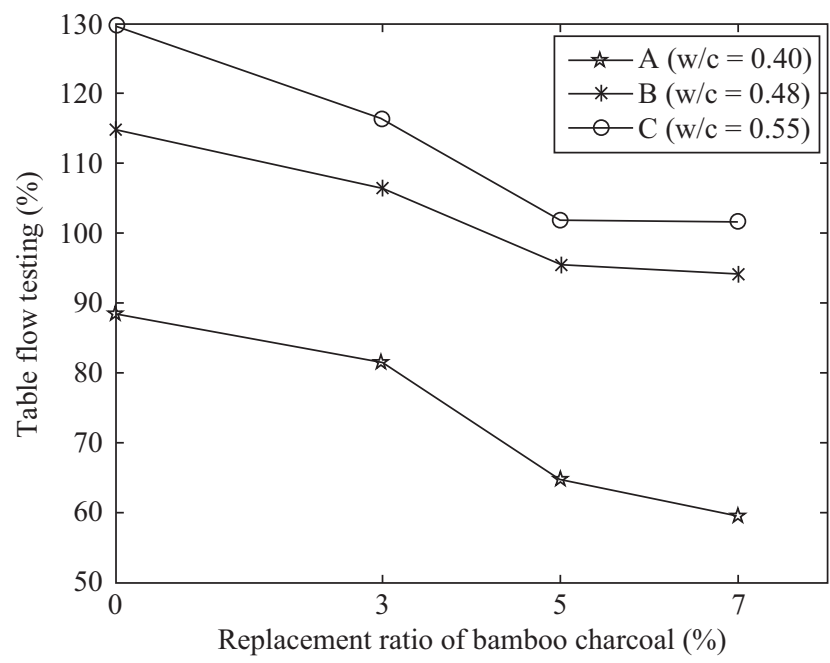

Fig. 2. The flow table testing result with respect to the charcoal replacement ratio.

\section{TEST RESULTS AND DISCUSSION}

As mentioned in section 3, the tests for particular properties of the cement mortar in both freshly mixed and hardened status were designed and carried out. The experimental testing data were further presented into figure form and discussed in this section.

\section{Flow Table Testing}

The readings of the flow table testing [5] for the mortar were drawn with respect to the water/cement (w/c) ratio as shown in Fig. 2, where the ratio of the charcoal replacement is also shown. It is observed that corresponding to the increase of the w/c ratio, the flow table reading is increased. It means that the consistency of fresh mixture is better for material with higher moisture content. Although the replacement ratio of charcoals varies, this trend remains. However, when the ratio of replacement of charcoal is increased, the flow table reading will be reduced showing that the bamboo charcoal may influence the consistency of fresh mortar adversely.

\section{Setting-Time Testing}

The setting time for initial set and final set of fresh mixtures of cement mortar was both measured. Shown in Fig. 3 is the initial setting time corresponding to the replacement ratio of charcoal. It shows that when the replacement ratio is increased the initial setting time will be reduced. When various w/c ratios were applied it shows that the higher w/c ratio mixture has the longer setting time while the trend for the decreasing of setting time is a bit different for mortars with various replacement ratio of bamboo charcoals. But generally, the initial setting time drops almost in a linear trend with respect to the increase of replacement ratio of bamboo charcoals.

The final setting time is shown in Fig. 4, where similar to initial setting behavior, the final setting time is reduced 


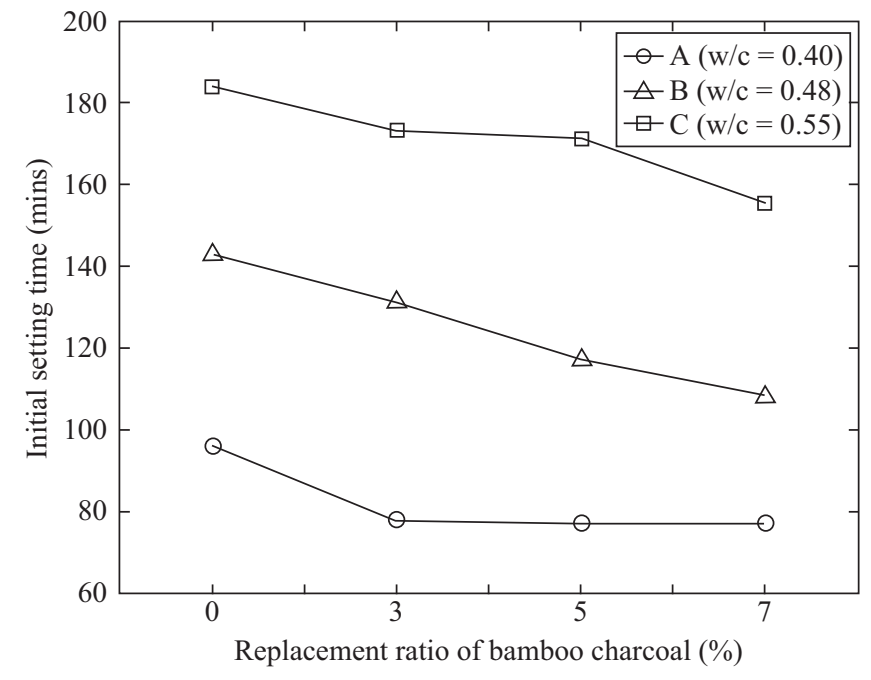

Fig. 3. The initial setting time with respect to the replacement ratio of bamboo charcoals.

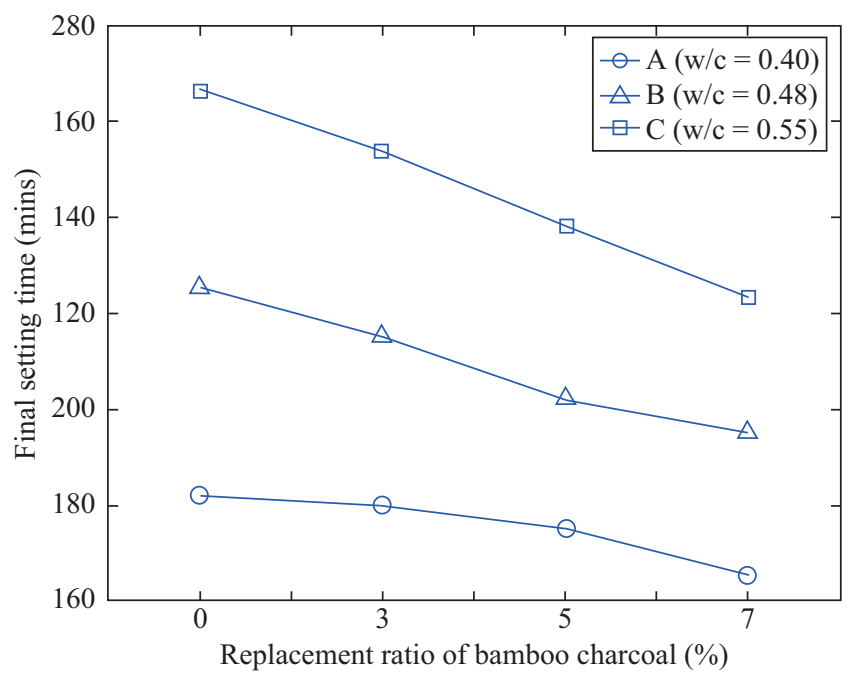

Fig. 4. The final setting time with respect to the replacement ratio of bamboo charcoals.

corresponding to the increase of replacement ratio of charcoal to the aggregate. The linear relationship of decreasing time of final set with respect to the increase of replacement ratio of bamboo charcoals is much more obvious for the final setting time. However, the total duration of time needed for complete setting seemed not to be influenced by the charcoal replacement. Only in the high w/c ratio group (group C), the higher charcoal replacement showed less time needed for complete setting, which is about $17 \%$ shorter compared to the group without any replacement for aggregate.

\section{Absorption Capacity and Absorption Rate Testing}

The moisture absorption capacity testing based on ASTM C642 [7] was performed for specimens with various replacement ratios of the charcoal and w/c ratio. Indicated in Fig. 5 is

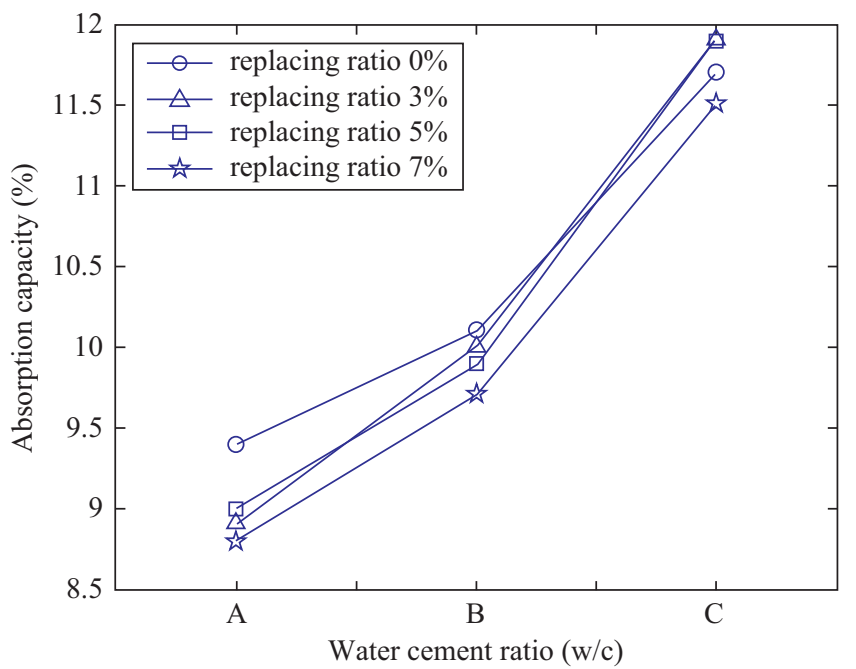

Fig. 5. The absorption capacity of the mortar with respect to various replacement ratios of the bamboo-charcoal.

the absorption capacity with respect to various w/c and replacement ratio of charcoal. It is observed that the increase of the replacement ratio of the bamboo charcoal would not significantly increase the absorption capacity of the cement mortar even though the increase of absorption due to the increase of w/c ratio is very obvious.

In some cases such as in the low $\mathrm{w} / \mathrm{c}$ ratio (group $\mathrm{A}, \mathrm{w} / \mathrm{c}=$ 0.4 ), the increase in the replacement of the bamboo charcoal may eventually reduce the moisture absorption capacity of the mortar. This is probably due to the reduction of the larger voids in the cement mortar, which are filled up by the very fine bamboo charcoal particles. It also shows that as long as the replacement of the charcoal is in a reasonable small amount, the moisture absorption capacity can be reduced when compared to the traditional cement mortar.

The absorption rate of the mortar in terms of gram per root-square of minute as shown in Fig. 6 also shows a similar trend that when the replacement ratio of the bamboo charcoal is higher the absorption rate is generally smaller, particularly for the mixtures of low w/c ratio. However, in the higher w/c rate mixtures $(\mathrm{w} / \mathrm{c}=0.55)$, the moisture absorption rate is generally high except for mixtures of $5 \%$ replacement ratio group.

\section{Compressive Strength Testing}

From results of the compressive strength tests for the cement mortar cured in the lime water for 28 days as shown in Fig. 7, the specimen with $5 \%$ replacement ratio of charcoals has the highest strength while the ones with $3 \%$ and $7 \%$ replacement ratio of charcoals have relatively smaller compressive strength. However, all groups of specimen with small amount of bamboo charcoal replacement for the aggregates are improved on compressive strength compared to the group without any replacement of bamboo charcoals. The increase in the compressive strength could reach up to $20 \%$ as shown in the group with $5 \%$ replacement ratio of charcoal. The 


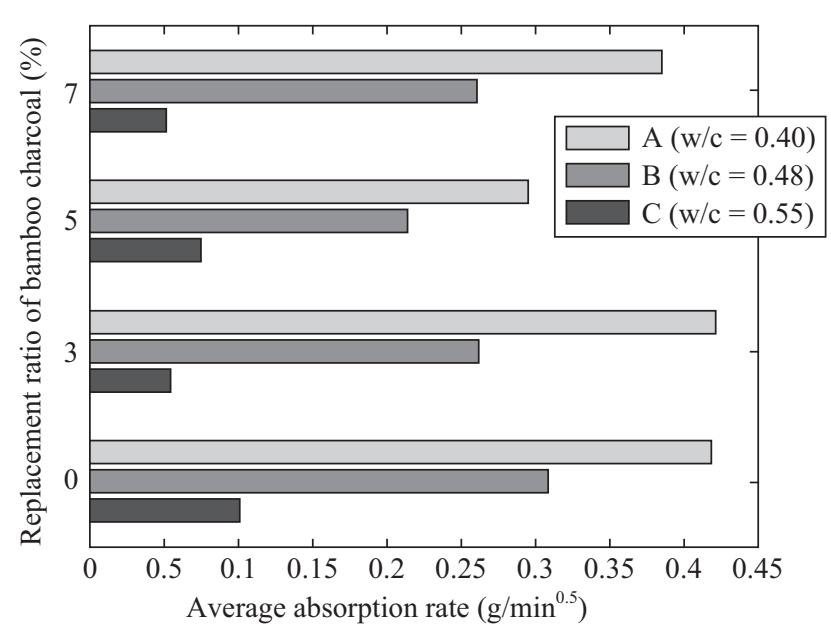

Fig. 6. The moisture absorption rate of the mortar with respect to various replacement ratios of the bamboo-charcoal.

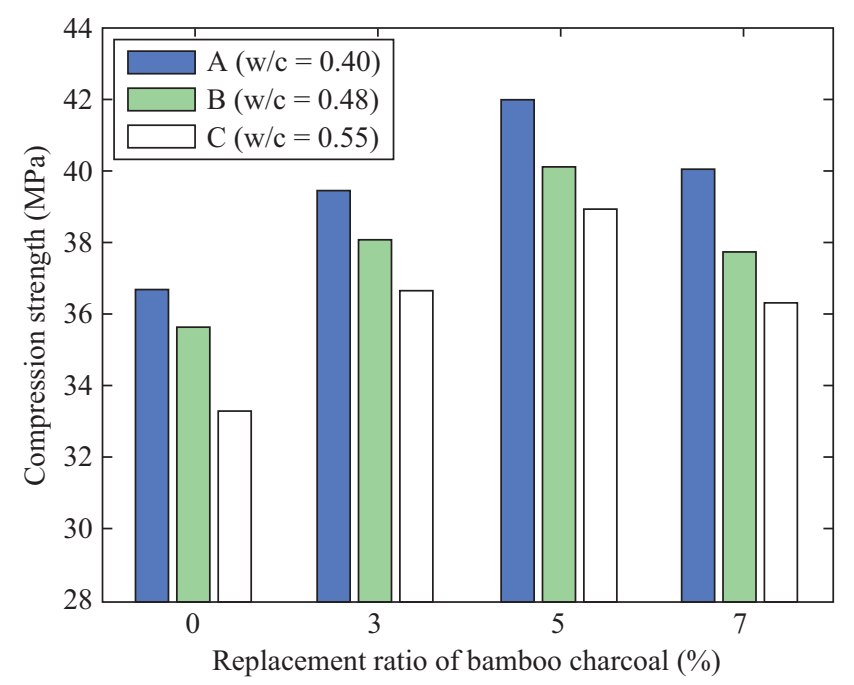

Fig. 7. The compression strength of cement mortar cured for 28 days with respect to various replacement ratios of charcoals.

influence of the w/c ratio is obvious for all three groups of replacement ratio such that specimens with lower w/c ratio have higher strength. This trend remains for all groups with various replacement ratios.

\section{Sulfate Resistant Testing}

In order to know the durability performance in an extreme polluted aqueous environment for the charcoal added cement mortar, the wet-cycle test for the sulfate resisting capability was performed according to AASHTO-T104 [1]. Similarly, specimens of three water/cement ratios along with four ratios of replacement of bamboo charcoals were repeatedly immersed into the solution of sodium sulfate and then dried out for five cycles. Then the deformations, distortions or volume changes of the specimen were examined and recorded; the weight loss of the specimen was also measured for each specimen. The increment of moisture absorption rate was

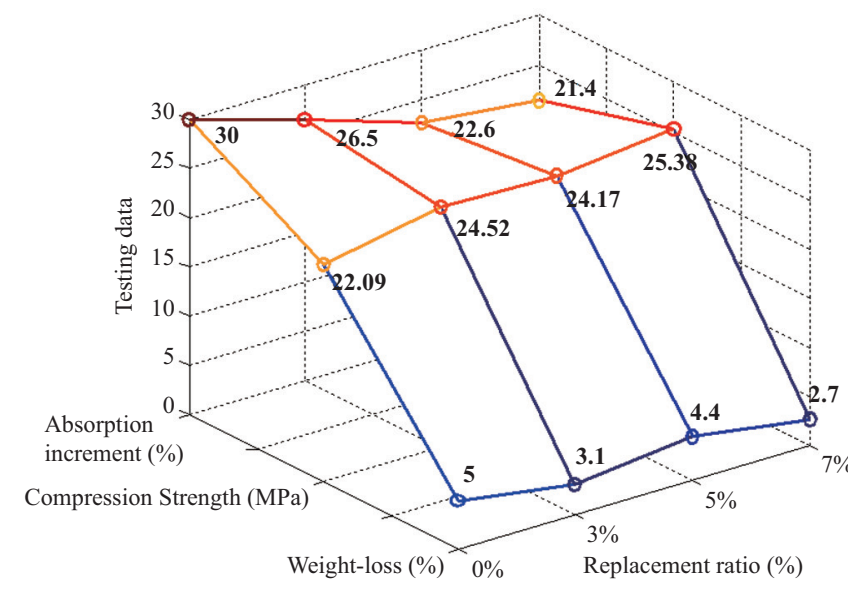

(a)

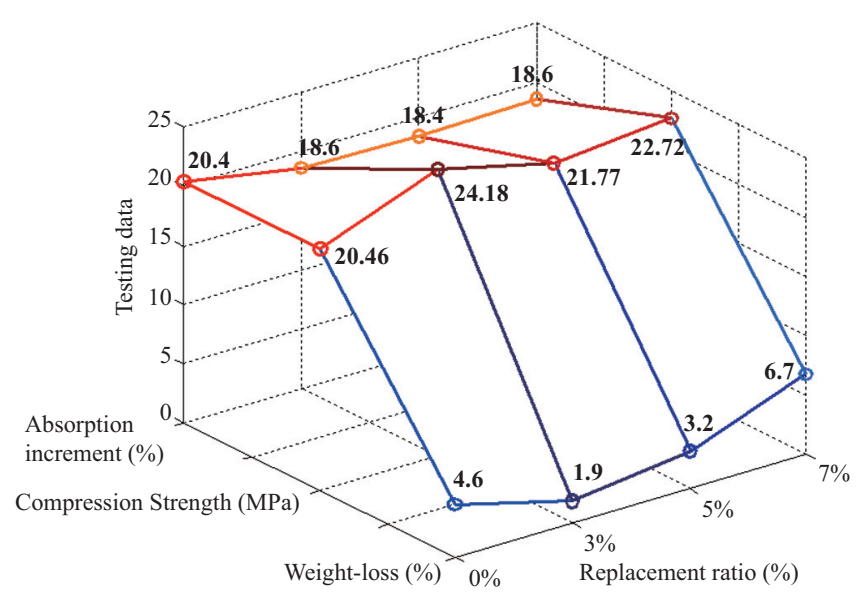

(b)

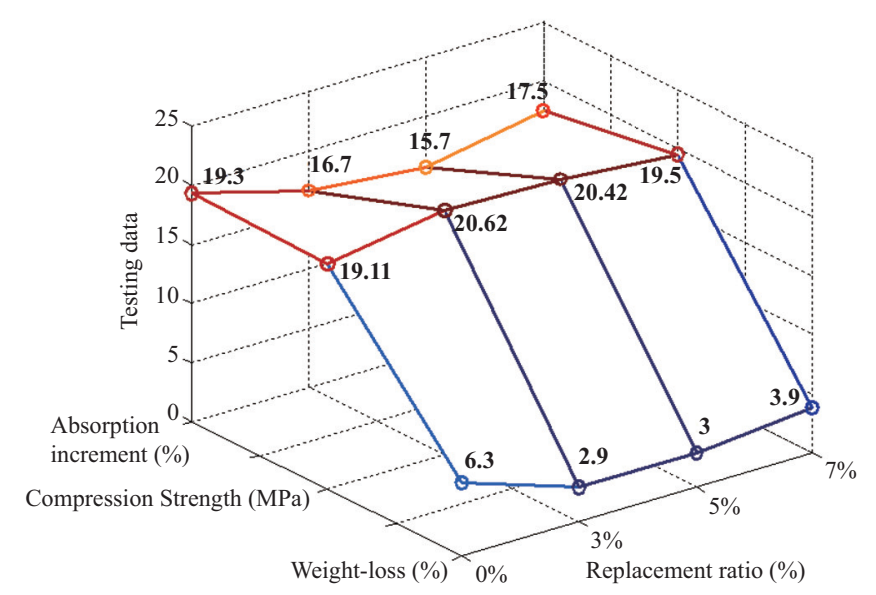

(c)

Fig. 8. (a) Results of sulfate resistant test $(w / c=0.40)$, (b) Results of sulfate resistant test $(w / c=0.48)$, and $(c)$ Results of sulfate resistant test $(w / c=0.55)$.

evaluated and compressive strength of the specimen was also tested. By combining these experimental test results together, the sulfate resistant capability of the material can be evaluated as observed in the 3-D figures as shown in Figs. 8(a)-(c) for specimens with various water/cement ratio, respectively. 


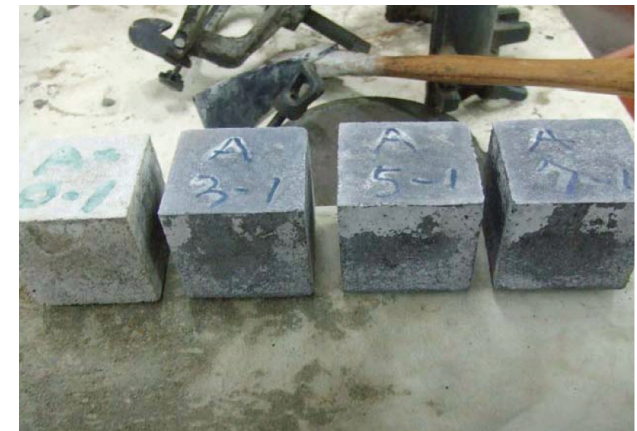

(a)

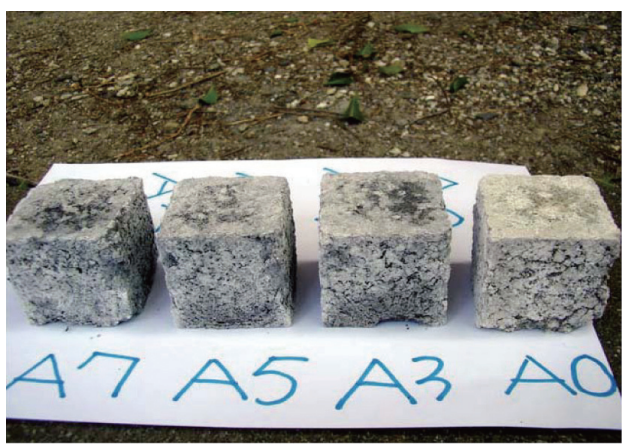

(b)

Pic. 1. (a) Eroded status of specimens before sulfate resisting test (group $A, w / c=0.4$ ) and (b) Eroded status of specimens after sulfate resisting test (group $\mathrm{A}, \mathrm{w} / \mathrm{c}=\mathbf{0 . 4})$.

It is clear from the results of a series of sulfate-resisting tests that specimens with lower measurement of weight-loss and smaller increment of moisture absorption capacity have higher compressive strength and therefore the sulfate-resisting capability or soundness is better. Based on these principles, more the shape of a gable-like shape becomes in the figures, better the sulfate-resisting capability is for the specimen. According to Fig. 8(a), when the w/c ratio $=0.40$, all specimens with replacement of certain ratio of charcoals have better sulfate resisting capability compared to the one without any charcoal replacements in the fine aggregate that has worst performance on sulfate resisting test. The group of $7 \%$ charcoal replacement has best performance in sulfate-resistant capacity. For the specimens of $0.48 \mathrm{w} / \mathrm{c}$ ratio as shown in Fig. 8(b), it seems that $3 \%$ replacement ratio of the charcoal has best performance on the sulfate resisting capability while the one without any charcoal replacements in the fine aggregate, again, has worst sulfate resisting capability. For the specimens of $0.55 \mathrm{w} / \mathrm{c}$ ratio as shown in Fig. 8(c), all ratios of replacement of bamboo-charcoal have better sulfate resisting capability than the one without any charcoal replacement. This time the specimen of $7 \%$ charcoal replacement performed a little worse compared to the other two groups with smaller ratios of replacements.

After repeatedly immersed into and dried out from the sodium sulfate solution for five cycles, the variation of the material is obviously observed from the distortion, deformation and volume change of the tested specimens. Picture 1(a), 1(b),

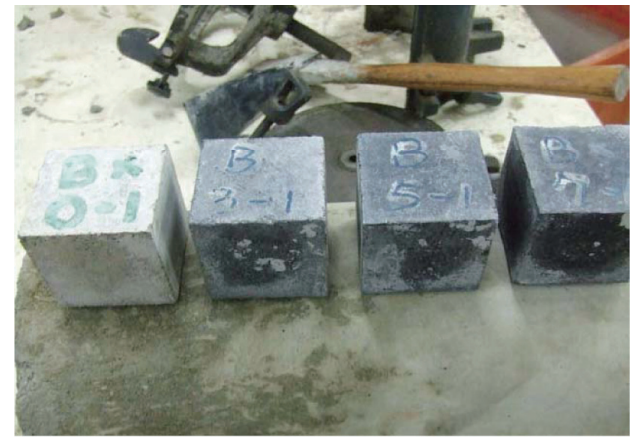

(a)

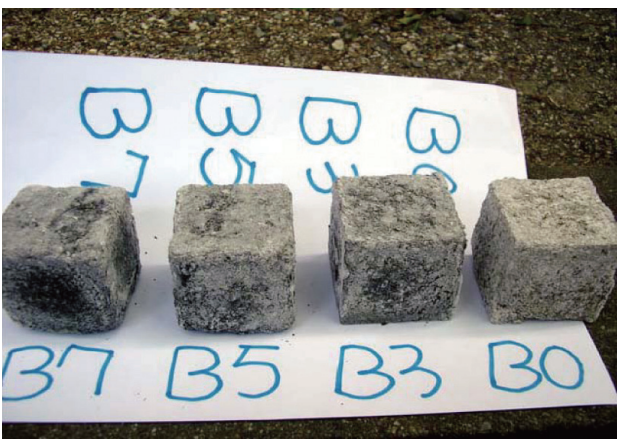

(b)

Pic. 2. (a) Eroded status of specimens before sulfate resisting test (group $B, w / c=0.48$ ) and (b) Eroded status of specimens after sulfate resisting test (group $B, w / c=0.48)$.

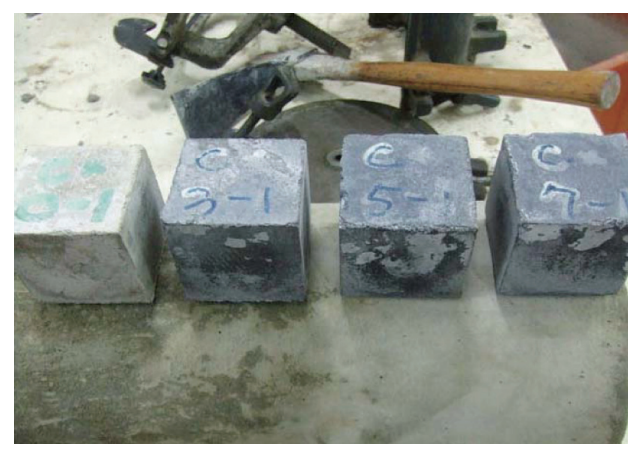

(a)

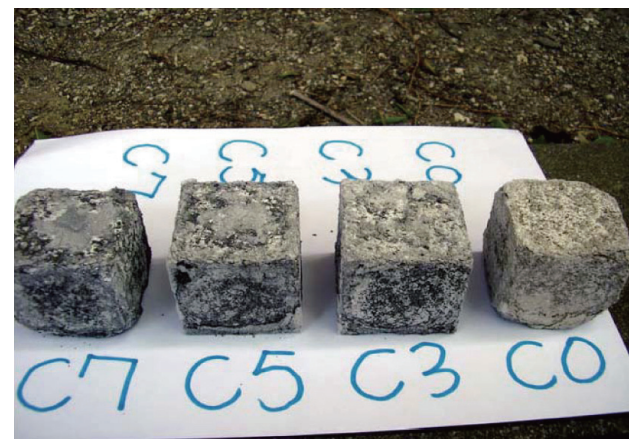

(b)

Pic. 3. (a) Eroded status of specimens before sulfate resisting test (group $\mathrm{C}, \mathrm{w} / \mathrm{c}=\mathbf{0 . 5 5}$ ) and (b) Eroded status of specimens after sulfate resisting test (group $\mathrm{C}, \mathrm{w} / \mathrm{c}=\mathbf{0 . 5 5}$ ). 

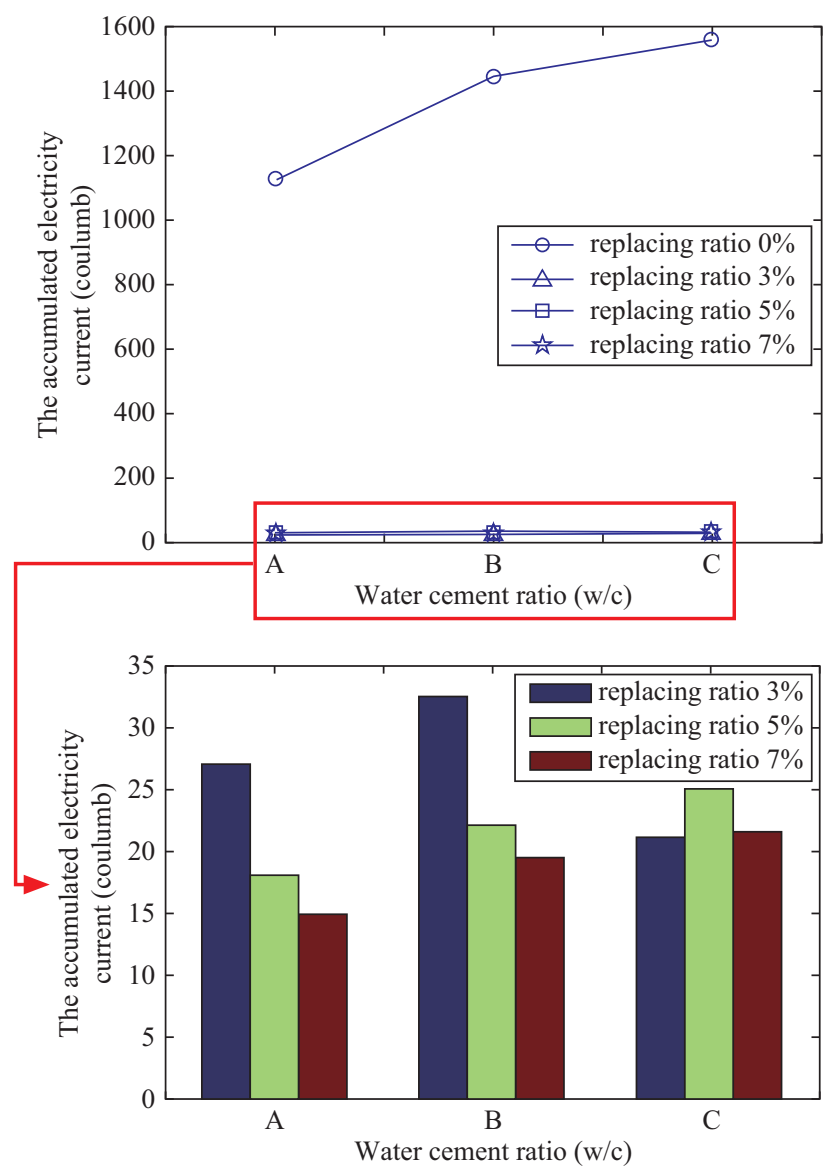

Fig. 9. The electron permeation test for the mortar with various bamboo charcoal replacement ratios.

2(a), 2(b), 3(a) and Picture 3(b) present the sulfate eroded status of each group of specimens with various water cement ratios from $\mathrm{w} / \mathrm{c}=0.40,0.48$ to $\mathrm{w} / \mathrm{c}=0.55$ before and after the sulfate-resisting test. It clearly shows the erosion effect induced by the sodium sulfate on the specimens. It is also observed from these pictures that without any charcoal replacement the erosion status appeared to be very significant no matter what $\mathrm{w} / \mathrm{c}$ ratio is for the specimen.

\section{Chloride Permeability Testing}

For the chloride penetration testing, a standard test based on ASTM C102 using electrical indication for the chloride ion penetration ability was performed. As shown in Fig. 9, the chloride penetration ability in terms of coulombs is generally increased with respect to w/c ratios in the traditional cement mortar. However, when the bamboo charcoals are applied the electrical current indicating the chloride penetration ability is significantly reduced, of which the reduction is about $98 \%$.

As shown in the lower part of Fig. 9, no mater what w/c ratio is applied, the reduction of the penetration ability of chloride due to the application of bamboo charcoal is very significant and obvious. Corresponding to the variation in the replacement ratio of the charcoal, the penetration ability of

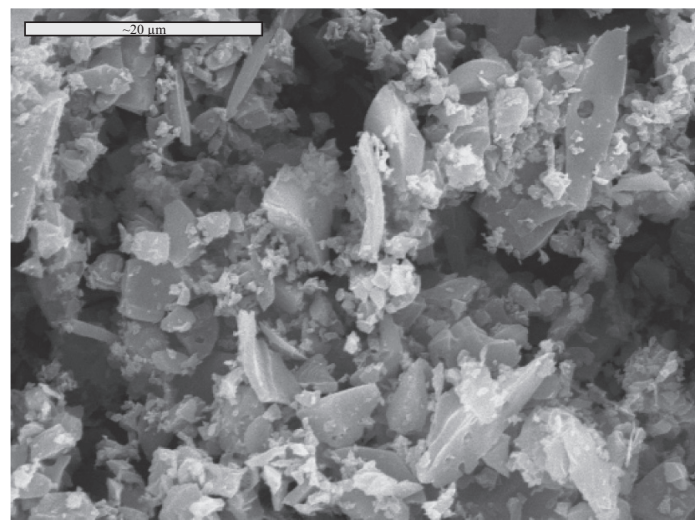

Pic. 4. Microscopic view of bamboo charcoal amplified in 2000 times.

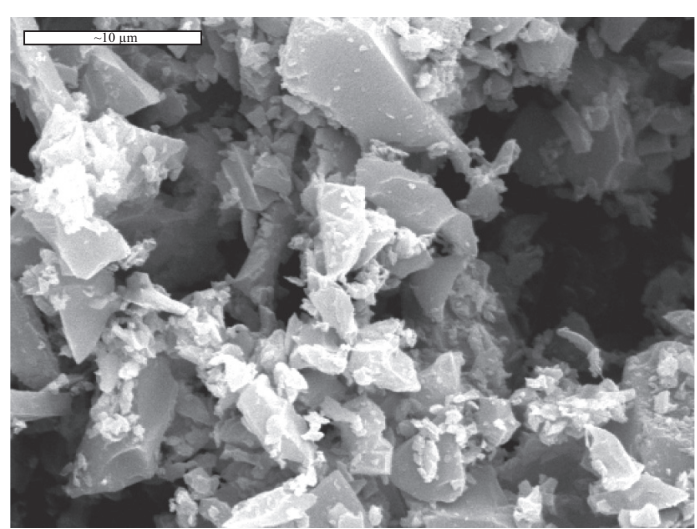

Pic. 5. Microscopic view of bamboo charcoal amplified in 3000 times.

chloride is also influenced. However, compared to the penetration ability of chloride in the traditional cement mortar, these differences are very minor and almost negligible.

\section{Microscopic Structures of Mortar with Bamboo-Charcoals}

The microscopic structures of both bamboo-charcoals and cement mortar with small amount of bamboo-charcoals were examined through SEM (Scanning Electronic Microscope), where the composition of inner structure can be amplified as large as 3000 times. The typical structures of a bamboocharcoal are presented in Picture 4 and Picture 5, where the enlargement of the structure in the picture is 2000 times and 3000 times, respectively. Since charcoals would not react with chemical compounds of the cement or cement-mixture, it is expected that the charcoal ingredients can be distinguished from structure of the mortar by referring to these two pictures. Picture 6(a) to Picture 6(c) present an enlarged typical structures of a cement mortar with bamboo-charcoals, where the bamboo-charcoal constituents can clearly be observed in the structures. Due to the fact that charcoal's size is much smaller compared to the aggregate, it is expected that the replacement of the charcoals to the aggregate may reduce the pores in the mortar and eventually, enhance the impermeability and strength 


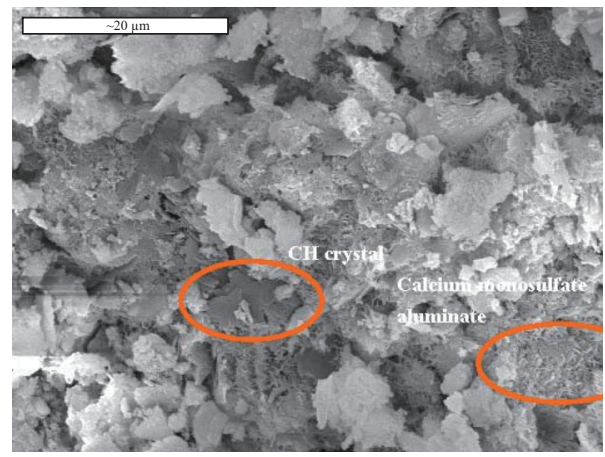

(a)

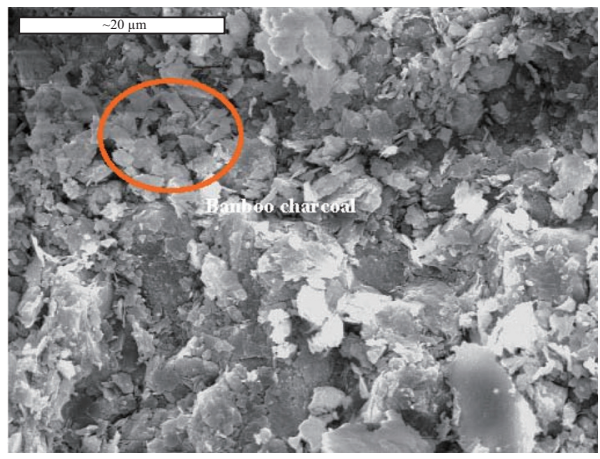

(b)

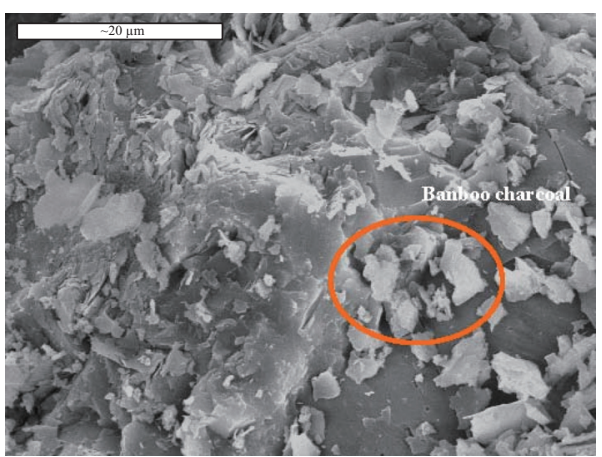

(c)

Pic. 6. (a) Microscopic view of cement mortar with bamboo charcoal amplified in 2000 times, (b) Microscopic view of cement mortar with bamboo charcoal amplified in 2000 times, and (c) Microscopic view of cement mortar with bamboo charcoal amplified in 2000 times.

of the mortar. That is already verified in the relevant experimental tests and it is also found from the SEM pictures that the pores in the mortar with charcoals are not significant.

\section{CONCLUSION}

In the series of tests for the cement mortar with partial replacement of fine aggregates with bamboo charcoal, it is found that the bamboo charcoal may influence the consistency of fresh mortar adversely. The setting time of fresh mortar mixtures drops almost linearly with respect to the increase of replacement ratio of bamboo charcoals. The variation of the replacement ratio for the bamboo charcoal seems to have little influence on the absorption capacity of moisture. However, in terms of the absorption rate, the increase in the replacement ratio of the bamboo charcoal may reduce the absorption rate of the mortar, particularly for the low water-cement ratio mixtures.

The highest strength of the mortar occurs for the specimens with 5\% replacement ratio of charcoal. The replacement of bamboo charcoal may actually increase the compressive strength as high as $20 \%$ for the cement mortar. From the penetration test of chloride ions, it is found that the penetration ability of chloride is significantly reduced by the scheme of partial replacement of fine aggregates with bamboo charcoals, in which the reduction rate for the chloride penetration is as high as $98 \%$. From the results of a series of tests for sulfate resistant capability, where specimens with lower measurement of weight-loss and smaller increment of moisture absorption capacity and higher compressive strength represent a better capability to sulfate attacks. It shows that small amount of bamboo charcoal such as 3\% replacement ratio may significantly improve the sulfate resistant performance for the cement mortar.

It is concluded that very small amount of replacement of aggregates in cement mortar with bamboo charcoal may significantly improve the properties of the cement mortar in both fresh mixture and hardened form. It is also found that $5 \%$ of replacement of aggregates with bamboo charcoal can produce a cement mortar that may effectively reduce the attack of chloride compounds and has a better strength and impermeability.

\section{ACKNOLOLEDGMENTS}

This paper has been financially supported in part by the National Science Council of Republic of China (Taiwan) under grants NSC95-2221-E110-144. It is gratefully acknowledged here.

\section{REFERENCES}

1. AASHTO-T104, Standard Method of Test for Soundness of Aggregate by use of Sodium Sulfate or Magnesium Sulfate, American Association of State Highway Transportation Officials.

2. ASTM C109/109M-08, Standard Test Method for Compressive Strength of Hydraulic Cement Mortars (using 2 in cubes), American Society of Testing Materials (2008).

3. ASTM C1202-97, Standard Test Method for Electrical Indication of Concrete's Ability to Resist Chloride Ion Penetration, American Society of Testing Materials (1997).

4. ASTM C191-08, Standard Test Method for Time of Setting of Hydraulic Cement by Vicat Needle, American Society of Testing Materials (2008).

5. ASTM C230/230M-08, Standard Specification for Flow Table for use in Tests of Hydraulic Cement, American Society of Testing Materials (2008).

6. ASTM C266-08, Standard Test Method for Time of Setting of Hydraulic Cement by Gillmore Needles, American Society of Testing Materials (2008).

7. ASTM C642-06, Standard Test Method for Density, Absorption and voids in Hardened Concrete, American Society of Testing Materials (2006). 
8. Bentur, A., Berger, R. L., Kung, J. H., Milestone, N. B., and Young, J. F., "Structure properties of calcium silicate pastes: II. Effect of curing temperature," Journal of The American Ceramic Society, Vol. 62, No. 7-8, pp. 362-366 (1983).

9. Brandt, A. M., Cement-based Composites: Materials, Mechanical Properties and Performance, E\&FN SPON, London (1995).

10. Cabrera, J. G. and Claisse, P. A., "Measurement of chloride penetration into silica fume concrete," Cement Concrete Composites, Vol. 12, No. 3, pp. 157-161 (1990)

11. Chen, H.-B., The Production of Bamboo Charcoal and Active Carbon, Master's Dissertation, Department of Forestry, National Pingtung University of Science and Technology, Pingtung, Taiwan (2003).

12. Jazairi, B. E. and Illston, J. M., "The hydration of cement paste using the semi-isothermal method of derivative thermogravity," Cement and Concrete Research, Vol. 10, pp. 361-366 (1980).

13. Lee, H. H., "Corrosion of SS41 iron-carbon based steel in Kaohsiung Harbor," 3rd Conference on Material Corrosion and Protection, Quingdau, China, pp. 500-508, (2002).

14. Lee, H. H. and Chang, P.-Y., "The damage inspection and safety assessment on steel-sheet pile wharf structural system," Proceedings of 2006
International Conference on Fracture and Damage Mechanics, Harbin, China (2006).

15. Lee, H. H., Chen, Y.-Y., and Shyue, S. W., "Investigation on the destruction of caisson type wharfs during Chi-Chi Earthquake in Taiwan," APACE Conference Proceedings, Dalian, China, pp.671-680 (2001).

16. Mangat, P. S. and Tu, S. C., "Chloride ingress in microsilica concrete," Cement Concrete Composites, Vol. 15, No. 4, pp. 215-221 (1993).

17. Mehta, P. K., Pozzolanic and Cementitiors Byproducts as Mineral Admixtures for Concrete - A Critical Review, American Concrete Institute Special Publication-79, Farmington Hills, pp. 1-46 (1983).

18. Mehta, P. K., Concrete Structure, Properties and Materials, Prentice-Hall Inc., New Jersey (1980).

19. Midgley, H. G. and Illston, M., "Penetration of chlorides into hardened cement pastes," Cement and Concrete Research, Vol. 14, No. 4, pp. $546-$ 558 (1984)

20. Mindess, S. and Young, J. F., Concrete, Prentice-Hill Inc., New Jersey (1981).

21. Young, J. F., The Science and Technology of Civil Engineering Materials, Prentice-Hall Inc., New Jersey, pp. 206-215 (1998). 